Military Technical College Kobry El-Kobbah, Cairo, Egypt

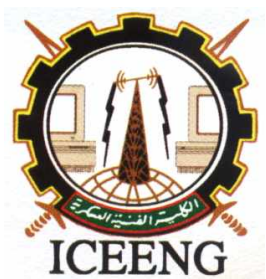

\section{$6^{\text {th }}$ International Conference on Electrical Engineering ICEENG 2008}

\title{
Transmission line fault detection \& location using discrete wavelet transform (DWT) and artificial neural network (ANN)
}

\author{
G. Kahela* \\ A. F. Abdel-Gawad** \\ W. Sabry*** \\ F. El-Bendary $* * * *$
}

\section{Abstract:}

This paper presents a new fault detector and locator scheme based on (DWT) and (ANN) for transmission lines. The main idea is to estimate faults detection, faulted phases distinguishing and faults location. These processes are obtained by calculating standard deviation of output signals from discrete wavelet analysis for all phase's currents signals. The final results will be obtained by training the proposed ANNs. The scheme has been implemented under Matlab-7- with utilization of toolboxes such as Simulink, WT and ANN. A typical $220 \mathrm{kv}$ transmission system with $100 \mathrm{~km}$ of transmission lines has been simulated to evaluate the studied scheme. The results show that the proposed scheme is efficient and easy in implement. Also, it is capable to detect, classify and locate varies faults within a half cycle after their occurrences.

\section{Keywords:}

Transmission Line, Fault Detection, Fault Location, Discrete Wavelet Transform, Artificial Neural Networks

* Asad Academy of Military Engineering, Aleppo, Syria

** University of Zagazig, Faculty of Engineering, Zagazig, Egypt

*** Egyptian Armed Forces

**** University of Benha, Faculty of Engineering, Shoubra, Egypt 


\section{Introduction}

Due to the increasing complexities of modern Electrical Power Systems (EPSs) and its comprising of different interacted elements, there always exists a possibility of disturbances and faults in EPS. So, it becomes necessary to identify different system faults faster and more accurately by using more powerful algorithms, and would be desirable to design a reliable and fast algorithm to classify different power system faults for various system parameters and faults types.

An overhead transmission line is one of the main components in any EPS. It exposed to the environment and the possibility of experiencing faults is generally higher than that on other main components [1]. So, the faults on power system transmission lines must be rapidly detected, determine accurately fault location, correctly fault classification and cleared as fast as possible for keeping on continuity, reliability and stability of EPS. In the past, many engineers have used and continue to use fault analysis programs to calculate the locations of transmission line shunt faults. These practices are satisfactory in some cases.

Nowadays, the use of microprocessor-based technology to monitor and protect power systems has made it possible to capture and store sufficient system information that can help to analyze power system disturbances.

The essential factor behind this new strategy is due to the competitive markets, in which the terms such as the continuity, dependability and reliability play an important role. Fault diagnosis on transmission lines requires more accurate and complex computation routines. Thus, the need for particular fault diagnosis algorithms is obvious $[2,3]$.

The research for fault diagnosis methodologies on transmission lines is an attractive area till present in order to have a better understanding of the problem essence and to develop advanced solutions.

As documented in the literatures. P.Makming et al. presented a new method to faults diagnosis in a transmission system. This is based on detecting high frequency components contained in a fault signal spectrum. The DWT of positive, zero sequence, traveling wave theory and phases current used in the analysis in order to classify fault types and to locate fault positions [4].

Tahar Bouthiba presented an application of ANN to fault detection and location in Extra High Voltage (EHV) transmission lines for high speed protection using terminal line data. The neural fault detector uses only instantaneous current and voltage values, while the neural fault locator uses the magnitudes at the fundamental frequency of the voltage and/or current phasors. A FeedForward Neural Network (FFNN) based on the supervised backpropagation learning algorithm was used to implement the fault detector and locators [1].

Thompson Adu et al. presented a new fault locator based on reactance method of 
fault distance estimation, using data from one terminal of transmission line. The technique compensates for errors caused by factors such as load flow and fault resistance. The calculation of the unsymmetrical fault has been operated by using the algorithm of positive, negative, zero sequence [2].

The aim of this paper is to develop an accurate fault diagnosis scheme for overhead transmission lines, where it is depending on the available information at only one terminal, by using DWT and ANN.

\section{Wavelet Transform}

\section{$\underline{2.1 \text { Basic Concepts }}$}

The main advantage of wavelet is its capability of providing accurate transient information in both frequency domain and time domain [5].

Wavelet analysis is a relatively new signal processing tool and is applied recently by many researchers in power systems due to its strong capability of time and frequency domain analysis. The two areas with most applications are power quality analysis and power system protection. The definition of Continuous Wavelet Transform (CWT) for a given signal $x(t)$ with respect to a mother wavelet $\psi(t)$ is [6]:

$C W T(a, b)=\frac{1}{\sqrt{a}} \int_{-\infty}^{\infty} x(t) \psi\left(\frac{t-b}{a}\right) d t$

Where: $\mathrm{a}$ is the scale factor and $\mathrm{b}$ is the translation factor. For CWT, $\mathrm{t}, \mathrm{a}$ and $\mathrm{b}$ are all continuous.

The application of wavelet transform in engineering areas usually requires Discrete Wavelet Transform (DWT), which implies the discrete form of $t, a$ and $b$ in (1). The representation of DWT can be written as:

$D W T(m, n)=\frac{1}{{\sqrt{a_{0}}}^{m}} \sum_{k} x(k) \psi\left(\frac{k-n b_{0} a_{0}^{m}}{a_{0}^{m}}\right)$

Where original $\mathrm{a}$ and $\mathrm{b}$ parameters in (1) are changed to be the functions of integers $\mathrm{m}, \mathrm{n}$ and $\mathrm{k}$ is an integer variable and it refers to a sample number in an input signal.

\subsection{Multiple Level Decomposition}

A very useful implementation of DWT, called multi-resolution analysis, is demonstrated in Fig.(1).

The original sampled signal $x(n)$ is passed through a high pass filter $h(n)$ and a low pass filter $l(n)$. Then the outputs from both filters are decimated by 2 to obtain the detail coefficients and the approximation coefficients at level $1\left(D_{1}\right.$ and $\left.A_{1}\right)$. The 
approximation coefficients are then sent to the second stage to repeat the procedure.

Finally, the signal is decomposed at the expected level [6, 7]. These cases are shown in Fig. (1).

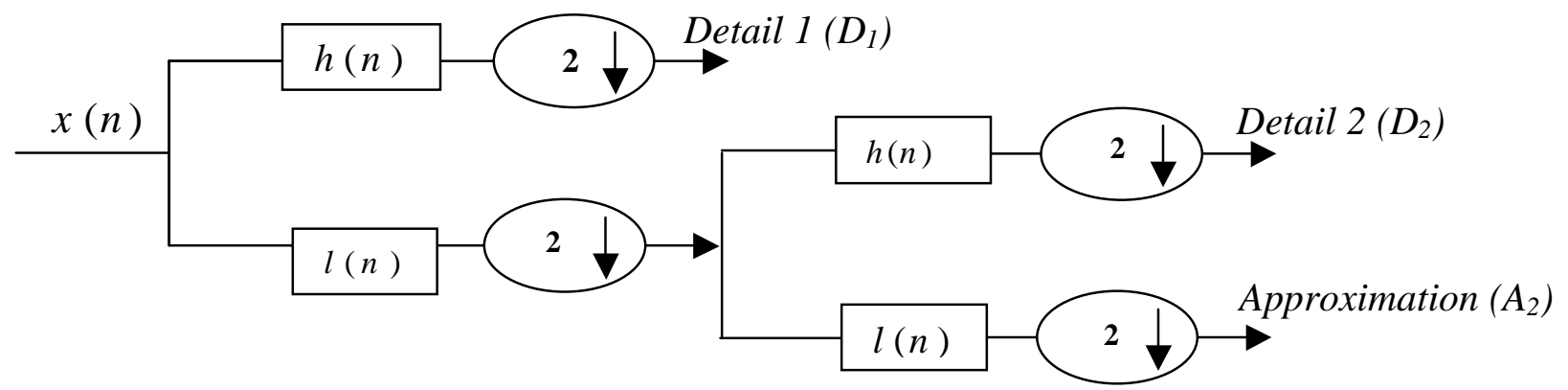

Fig. (1): The idea of wavelet multi-resolution analysis

If the original sampling frequency is $F$, the signal information captured by $D_{1}$ is between $F / 4$ and $F / 2$ of the frequency band. $D_{2}$ captures the information between $F / 8$ and $F / 4$, and $A_{2}$ retains the rest of the information of original signal between 0 and $F / 8$. By such means, we can easily extract useful information from the original signal into different frequency bands and at the same time the information is matched to the related time period.

\section{Artificial Neural Network}

Artificial Neural Networks (ANNs) are powerful in pattern recognition and classification. Consequently, various ANN-based algorithms have been investigated and implemented in power systems in recent years [8].

There are several types of neural networks used for power system protection. The Multi-Layer networks with Back Propagation (BP) algorithm is the one that was dominantly used in the power system studies since it can be easily realized.

The central idea of neural networks is adjusting the weight or bias parameters. So, the neural network is trained to do a particular job, or perhaps the network itself will adjust these parameters to achieve some desired end [9].

For network architectures can be used two or more of the neurons can be combined in a layer, and a particular network could contain one or more such layers. The three layer networks with back propagation structure are shown in Fig. (2). 


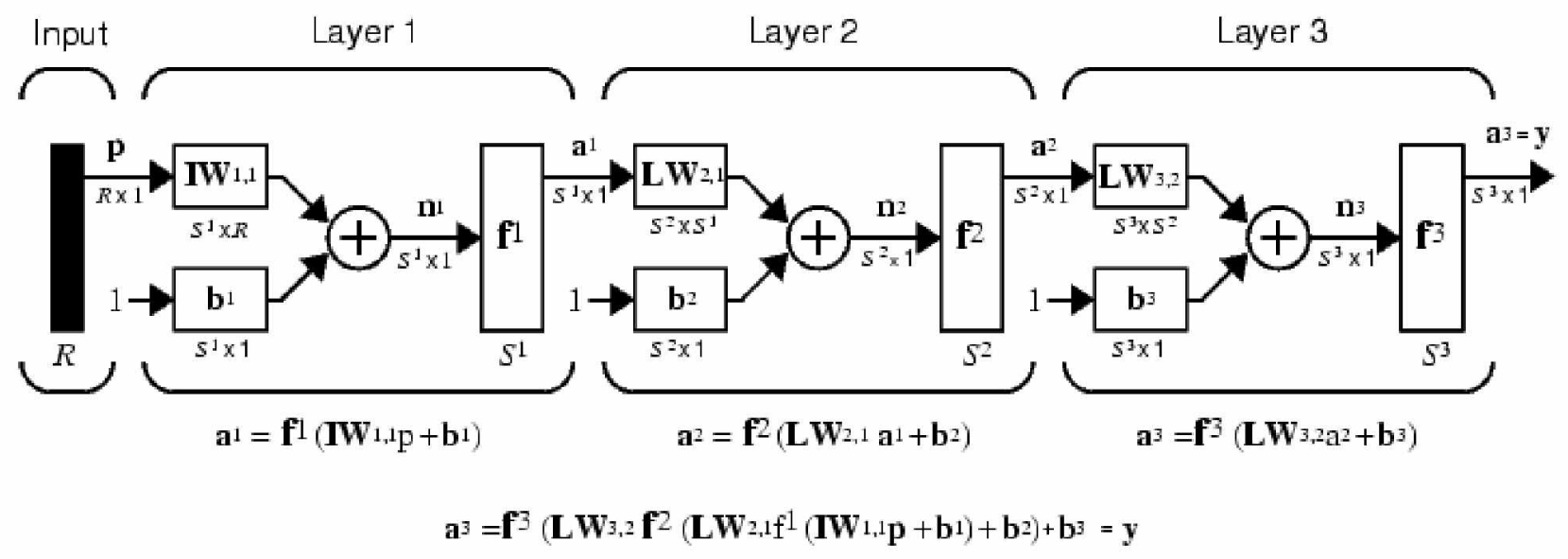

Fig. (2): Three layer network with back propagation structure

\section{Power System under Consideration}

The studied model of electrical power system consists of two alternators, two transformers, transmission line, bus bars, protection equipments and measurement equipments, as shown in Fig. (3).

Nominal power, line to line (LL) voltage, and frequency for generator:

$\mathrm{P}_{\mathrm{n}}=350 * 10^{6}[\mathrm{VA}], \mathrm{V}_{\mathrm{LL}}=13.8[\mathrm{kv}], \mathrm{f}_{\mathrm{n}}=60[\mathrm{~Hz}]$.

Nominal power and frequency for transformer:

$\mathrm{P}_{\mathrm{n}}=350 * 10^{6}[\mathrm{VA}], \mathrm{f}_{\mathrm{n}}=60[\mathrm{~Hz}]$.

Primary winding parameters:

$\mathrm{V}_{\mathrm{LL}}=13.8[\mathrm{kv}], \mathrm{R}_{1}=0.002[\mathrm{pu}], \mathrm{L}_{1}=0.08[\mathrm{pu}]$.

Secondary winding parameters:

$\mathrm{V}_{\mathrm{LL}}=220[\mathrm{kv}], \mathrm{R}_{2}=0.002[\mathrm{pu}], \mathrm{L}_{2}=0.08$ [pu].

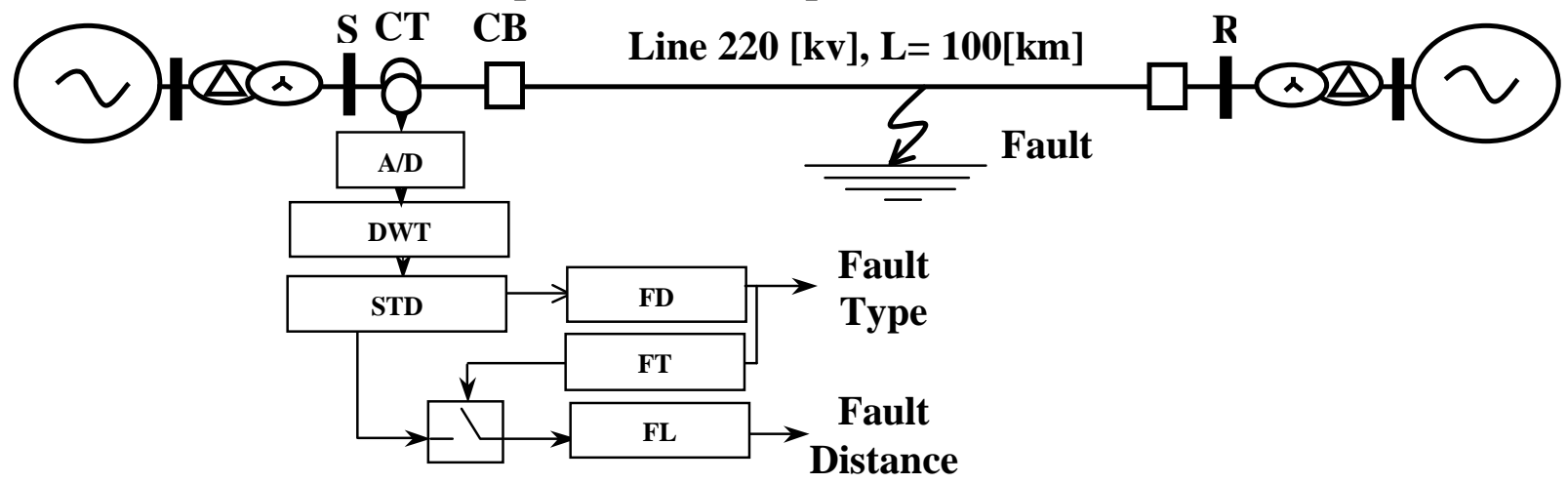

Fig. (3): System under study, CT: Current Transformer, CB: Circuit-Breaker, FD: Fault Detector, FT: fault type classifier, FL: Fault Locator. 


\section{Overall Scheme of Proposed Fault Diagnosis Algorithm}

Major functional blocks of the proposed fault diagnosis are shown in Fig. (4). Current signals $\left(\mathrm{I}_{\mathrm{A}}, \mathrm{I}_{\mathrm{B}}, \mathrm{I}_{\mathrm{C}}\right.$ and $\left.\mathrm{I}_{0}\right)$ at the transmission line end will be acquired by the relay through current transformers (CTs).

The signals pass through the Analog to Digital converter (A/D), the output of the (A/D) is analyzed using Discrete Wavelet Analysis (DWA) into three levels, so that every signal will be analyzed to three details $\left(D_{1}, D_{2}\right.$ and $\left.D_{3}\right)$ and three approximations $\left(A_{1}, A_{2}\right.$ and $\left.A_{3}\right)$. The standard deviations of $\left(D_{1}, D_{2}, D_{3}\right.$ and $\left.A_{3}\right)$ are calculated for $I_{A}, I_{B}$, $\mathrm{I}_{\mathrm{C}}$ and $\mathrm{I}_{0}$. After preprocessing, they will be fed to the fault detector (FD) to detect the fault type (A-G, B-G, C-G, AB-G, AC-G, BC-G, AB, AC, BC, ABC where A, B and C are related to the phases and $\mathrm{G}$ refers to the ground).

If the fault is detected, the fault locator (FL) estimates the distance to the fault in the transmission line due to fault type. The proposed fault detector (FD) is designed to indicate the presence or absence of a fault in all phases with and without ground.

The occurrence of the fault is determined by identifying the system status directly from instantaneous current data. The fault type classifier (FT) is designed to determine which switch will operate to fire the fault locator (FL) accordant to the fault type.

The fault locator (FL) is designed to estimate the distance of the fault in the transmission lines by using the same standard deviations matrix.

FD, FT and FL have many ANNs structures that will be illustrated in the communing sections. They are all located in only one relaying point near bus bar (S).

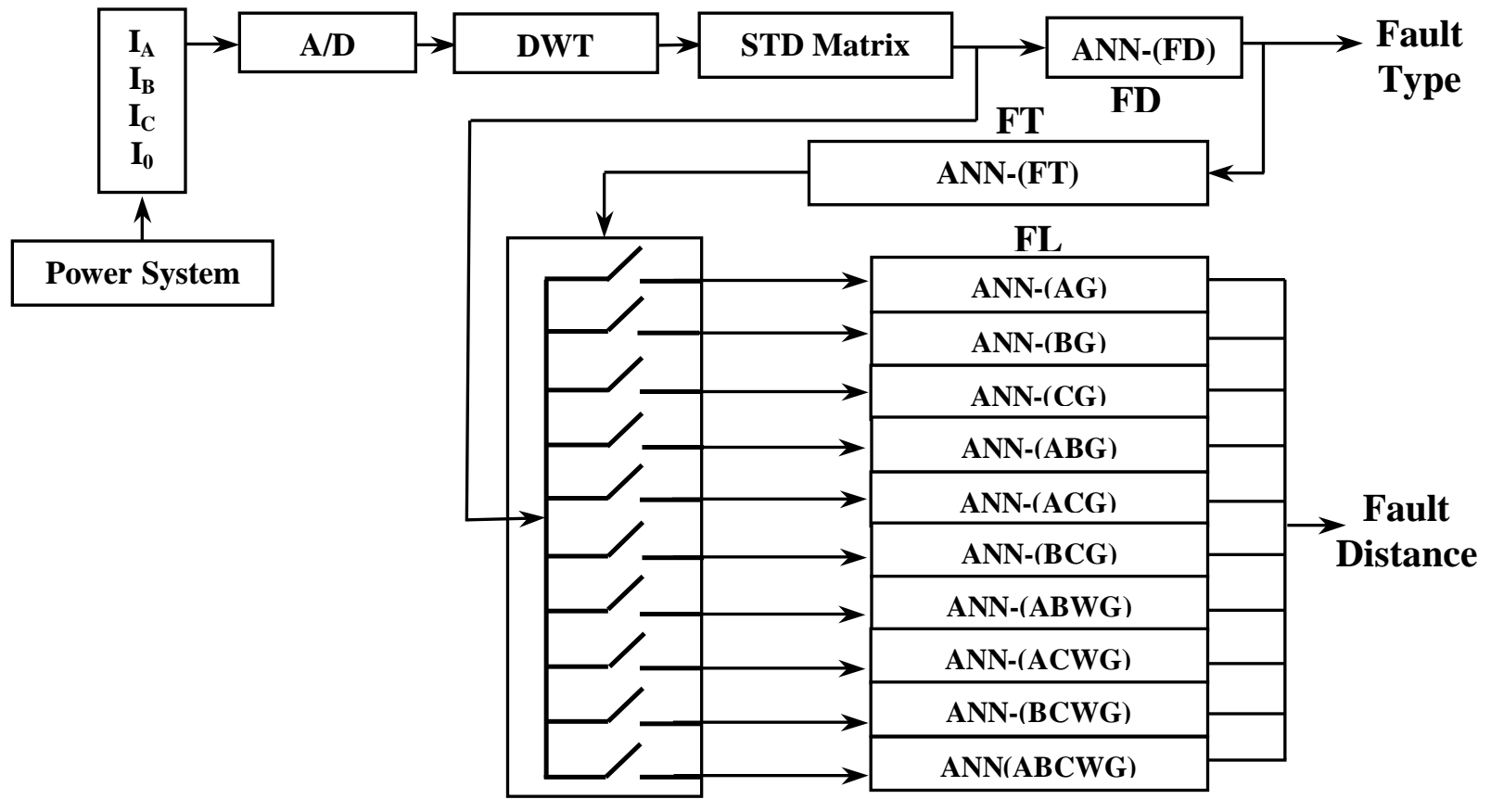

Fig. (4): Major blocks of fault diagnosis 


\section{The Structure of the Proposed Fault Diagnosis}

The design process of the ANNs related to fault detector, fault classifier and fault locator goes through the following steps [1]:

- Preparation of a suitable training data set that represents cases the ANN needs to learn.

- Selection of a suitable ANN structure for the given application.

- Training the ANN.

- Evaluation of the trained ANN using test patterns until its performance is satisfactory.

The training data set of an ANN should contain the necessary information to generalize the problem. Combinations of different fault conditions were considered and simulating different kinds of faults on the power system generated training patterns. Fault type, fault location, fault resistance and fault inception angle were changed to obtain training patterns covering a wide range of different power system conditions.

The selected parameter values for generate data training sets and test patterns for the ANNs are selected as follows:

- Fault location: from $15[\mathrm{~km}]$ to $85[\mathrm{~km}]$, by step $5[\mathrm{~km}]$.

- Fault inception angle: from 0 [deg] to 90 [deg], by step 15 [deg].

- Ground fault resistance has values: $(0.001,0.1,10,30$ and 50) [ $\Omega]$.

Fig.(5) shows the effect of the change in ground fault resistance, fault location, and fault inception angle on current wave for (A-G) fault, as an example. It represents one cycle with sampling rate of $5 \mathrm{e}-5 \mathrm{sec}$.
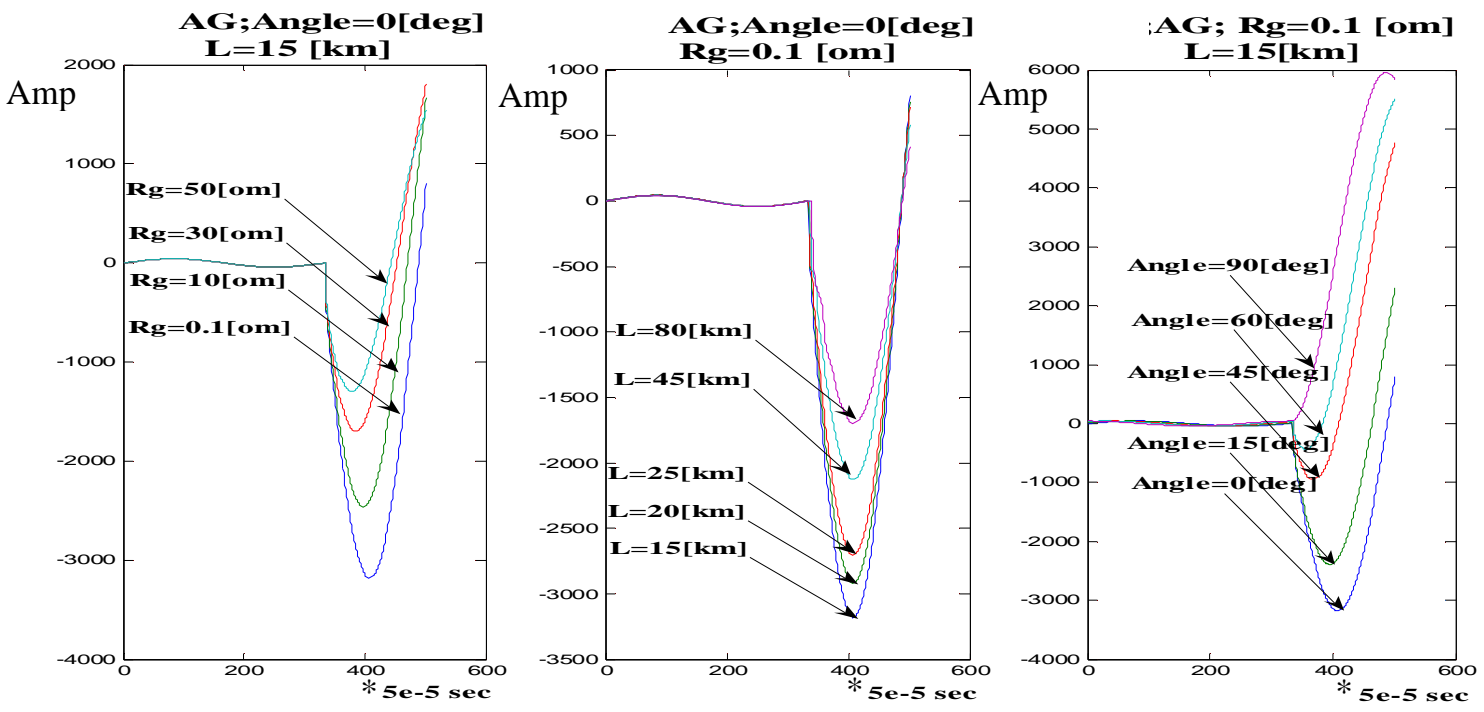

Fig. (5): The effect of ground fault resistance $\left(\mathrm{R}_{\mathrm{g}}\right)$, fault location $(\mathrm{L})$, and fault inception angle (Angle) on current wave for (A-G) fault 
The current wave forms are determined for all phases and neutral $\left(\mathrm{I}_{\mathrm{A}}, \mathrm{I}_{\mathrm{B}}, \mathrm{I}_{\mathrm{C}} \& \mathrm{I}_{0}\right)$ and analyzed by using DWT to get $\left(\mathrm{D}_{1}, \mathrm{D}_{2}, \mathrm{D}_{3}\right.$ and $\left.\mathrm{A}_{3}\right)$ for normal and fault cases. Then, the reconstructed signals are obtained. Next, the error between the original signal and reconstruction signal is calculated for all signals. Finally, the images are cleared for different cases, as shown in fig.(6), fig.(7), fig.(8) and fig.(9). The fault parameters have the following values:

$\mathrm{R}_{\mathrm{g}}=0.1[\Omega]$, fault inception angle $=0$ [degree], fault location $=15[\mathrm{~km}]$.

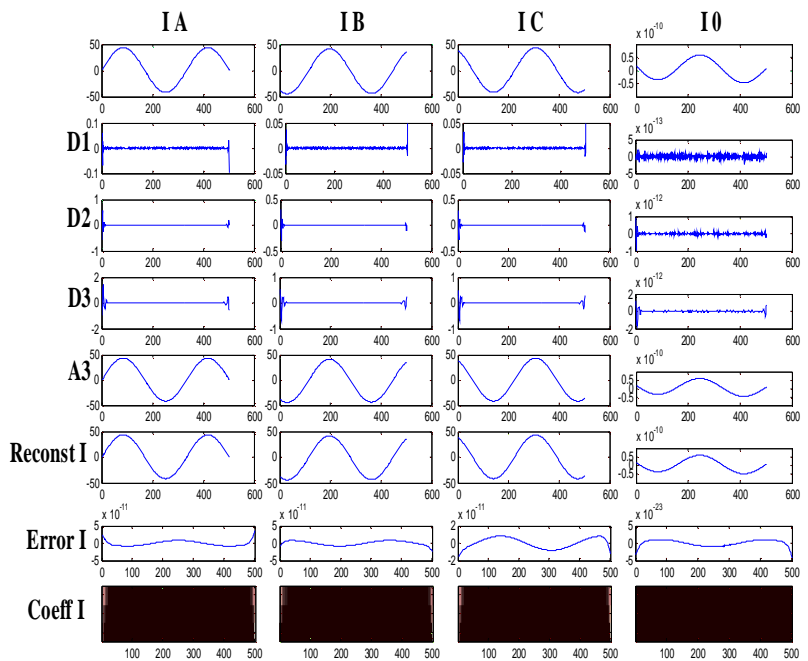

Fig.(6): The normal case.

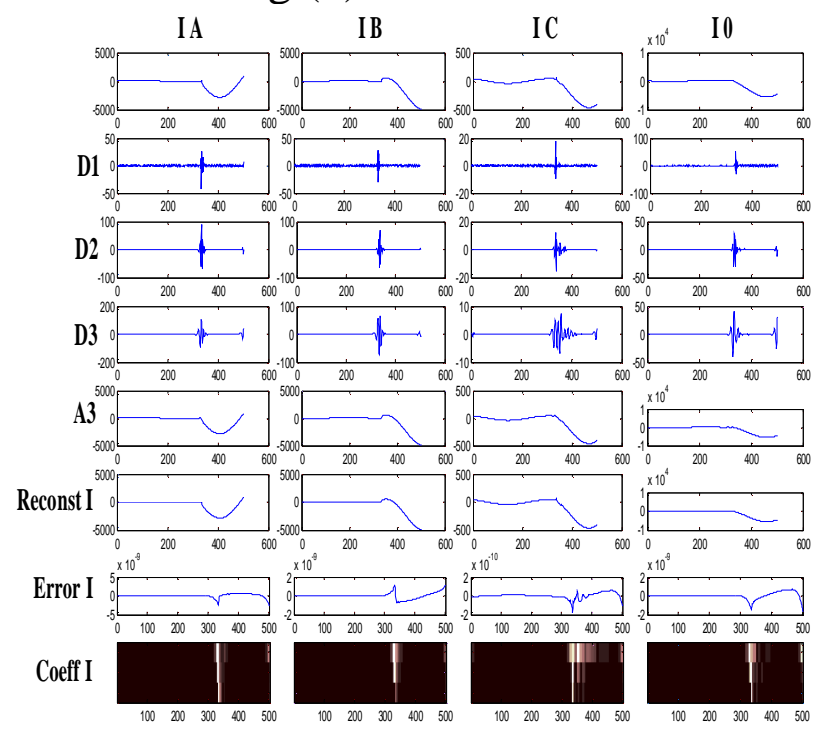

Fig.(8): the (AB-G) fault.

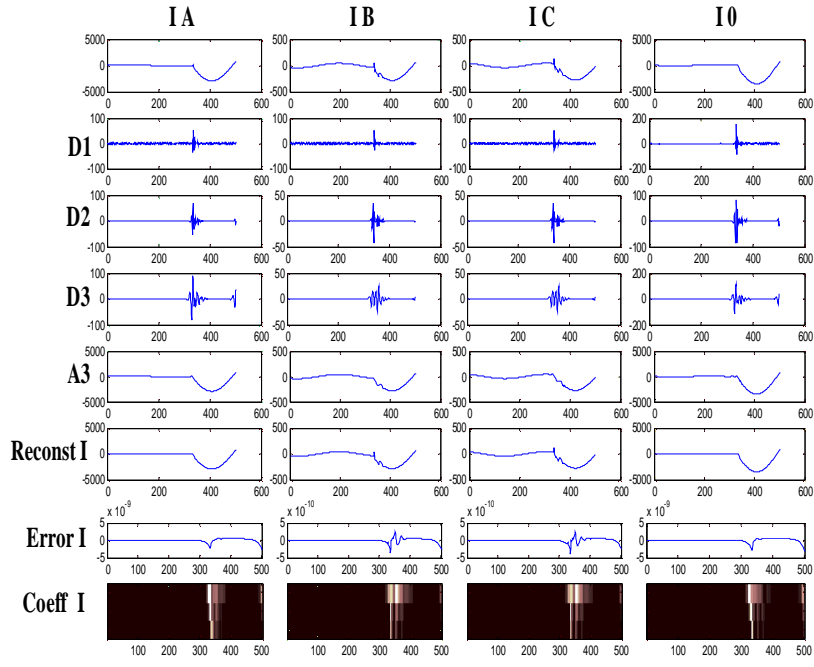

Fig.(7): the (A-G) fault.

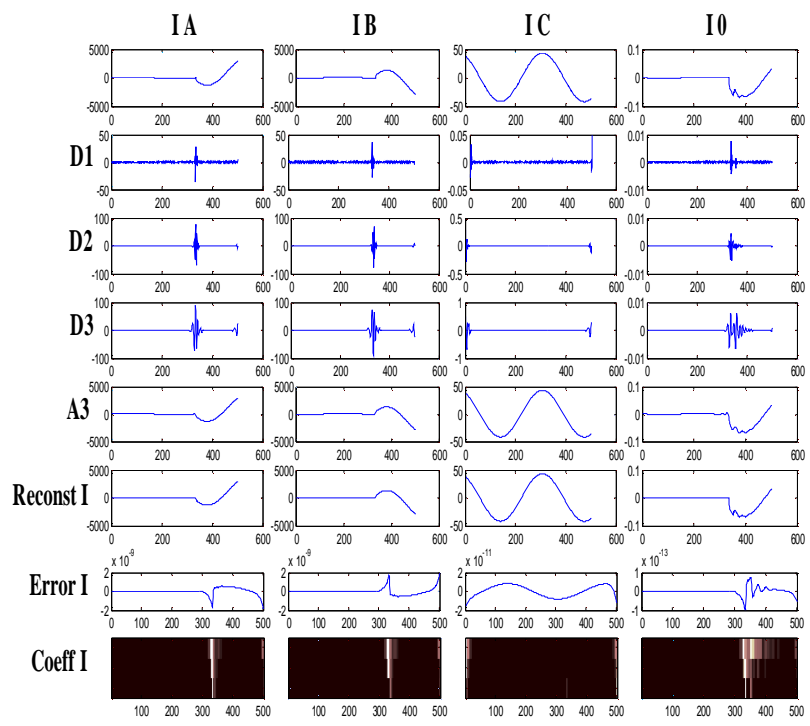

Fig.(9): the (AB) fault.

The standard deviations of $\left(D_{1}, D_{2}, D_{3}\right.$ and $\left.A_{3}\right)$ are calculated for $I_{A}, I_{B}, I_{C}$ and $I_{0}$. Fig. (10) shows the standard deviations (STD) for all fault types. 

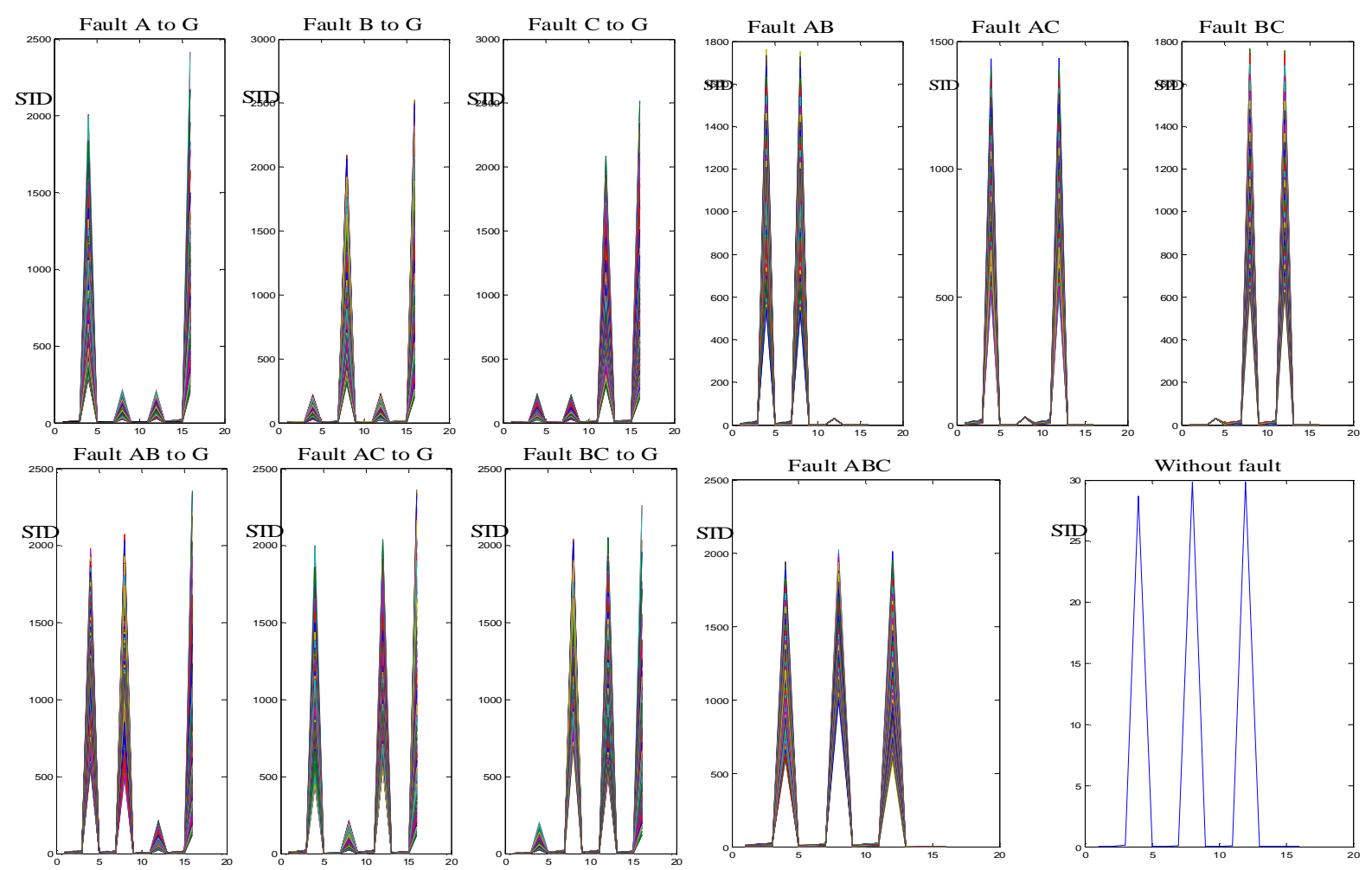

Fig. (10): The STD for details $D_{1}, D_{2}, D_{3}$ and approximation $A_{3}$ of $I_{A}, I_{B}, I_{C}$ and $I_{0}$.

\section{The Structure of the Fault Detector and Fault Locator}

The fault location task and fault classification can be formulated as a pattern classification problem. The fully connected three-layer feed-forward neural network (FFNN) was used to classify faulty/non-faulty data sets and the error back-propagation algorithm was used for training with sigmoid transfer function is TRAINBFG.

The numbers of neurons in the input layer was selected empirically through extensive simulations. Various network configurations were trained and tested in order to establish an appropriate network with satisfactory performances, which were the fault tolerance, time response and generalization capabilities. The inputs of neural networks are taken as the standard deviations (STD) for 4 samples of each current signal. This represents a moving window with a length of one cycle before fault and half cycle after fault. 
In order to construct a good neural network system, it is vitally important to train and test it correctly. So, with supervised learning, the ANN-FD, ANN-FT and ANN_FL are trained with various input patterns corresponding different types of fault (A-G, B-G, C-G, AB-G, AC-G, BC-G, AB, AC, BC, ABC) at various locations for different fault conditions (fault inception angles, ground fault resistances).

After a series of trials, the ANN-FD is chosen, consists of three layers: 6, 16 and 4 neurons, as shown in Fig. (11). The output of this ANN indicates the fault type by using 1 and 0 status ( 1 for faulty phases and 0 for healthy ones). The fault type classifier consists of to layers: 13, 10 neurons, as shown in Fig. (12). The inputs of fault type classifier are status of all phases and neutral, the output of this ANN is 1 or 0 for control on switch. The fault locator is consists of ten symmetrical ANNs represent the considered fault. Each ANN-FL is designed, consists of three layers: 6, 13 and 1 neurons, as shown in Fig. (13). The output of this ANN represents the fault location.

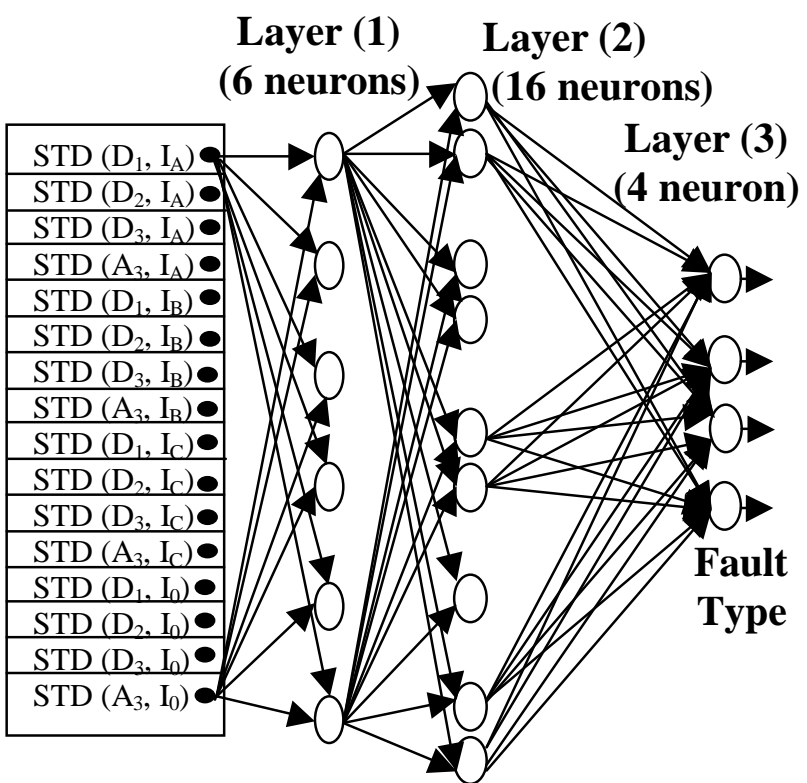

Fig. (11): ANN fault detector structure
Layer (1) Layer (2) (13 neurons) (10 neurons)

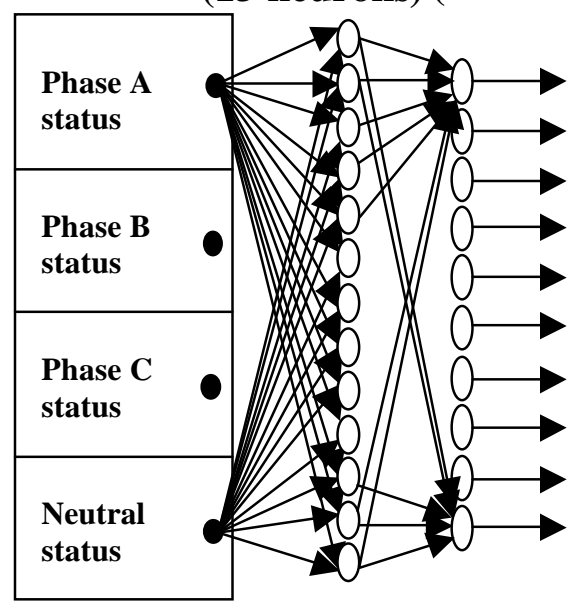

Fig. (12): ANN fault type classifier structure

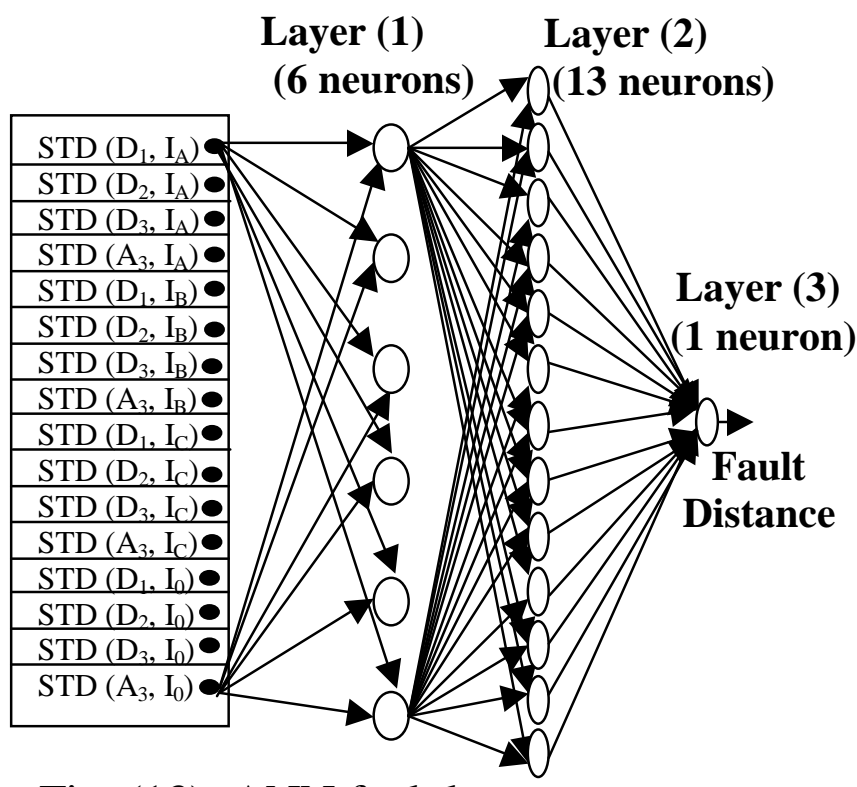

Fig. (13): ANN fault locator structure 


\section{$\underline{\text { 8. Test Results }}$}

In the next sections the performance of the FD and FL ANNs will be illustrated for training and testing processes.

\subsection{Test results of fault detector(FD)}

The Back-Propagation Algorithm with sigmoid transfer function (TRAINBFG) is used for training the ANN-FD. The results of training for recommendable goal 1e-08 are achieved after 956 epochs.

The network is tested by new fault cases that unseen through the training process. Table (1) shows the output status for different new fault types with different new conditions ( 1 for faulty phases and 0 for healthy ones).

Table(1): The output status for different new fault types

\begin{tabular}{|c|c|c|c|c|}
\hline $\begin{array}{c}\text { Fault } \\
\text { type }\end{array}$ & $\begin{array}{l}\text { Fault } \\
\text { status }\end{array}$ & $\begin{array}{c}\mathrm{L}=25[\mathrm{~km}] \mathrm{Rg}=0.01[\Omega] \\
\text { Angle }=15 \text { [degree }]\end{array}$ & $\begin{array}{c}\mathrm{L}=25[\mathrm{~km}] \mathrm{Rg}=0.01[\Omega] \\
\text { Angle }=37.5 \text { [degree] }\end{array}$ & $\begin{array}{c}\mathrm{L}=25[\mathrm{~km}] \mathrm{Rg}=0.01[\Omega] \\
\text { Angle }=67.5 \text { [degree] }\end{array}$ \\
\hline \multirow{4}{*}{ A-G } & $\mathbf{A}$ & $0.99995 \approx 1$ & 1 & 1 \\
\hline & B & $-1.8 \mathrm{e}-05 \approx 0$ & $-1.1 \mathrm{e}-05 \approx 0$ & $-1.3 \mathrm{e}-05 \approx 0$ \\
\hline & $\mathrm{C}$ & $-2.6 \mathrm{e}-05 \approx 0$ & $5.6 \mathrm{e}-05 \approx 0$ & $2.97 \mathrm{e}-05 \approx 0$ \\
\hline & $\mathbf{N}$ & $0.99 \approx 1$ & 1 & $0.99 \approx 1$ \\
\hline \multirow{4}{*}{ BC-G } & A & $-1.2 \mathrm{e}-05 \approx 0$ & $-1.2 \mathrm{e}-05 \approx 0$ & $-1.1 \mathrm{e}-05 \approx 0$ \\
\hline & B & 1 & 1 & 1 \\
\hline & $\mathrm{C}$ & 1 & 1 & 1 \\
\hline & $\mathbf{N}$ & $0.99 \approx 1$ & $0.99 \approx 1$ & $0.99 \approx 1$ \\
\hline \multirow{4}{*}{ AC } & $\mathbf{A}$ & 1.0 & $0.99 \approx 1$ & $0.99 \approx 1$ \\
\hline & B & $-8.0 \mathrm{e}-05 \approx 0$ & $3.0 \mathrm{e}-05 \approx 0$ & $1.05 \mathrm{e}-4 \approx 0$ \\
\hline & $\mathrm{C}$ & $0.99 \approx 1$ & 1 & 1.0 \\
\hline & $\mathbf{N}$ & $-1.9 \mathrm{e}-05 \approx 0$ & $9.4 \mathrm{e}-05 \approx 0$ & $2.1 \mathrm{e}-4 \approx 0$ \\
\hline \multirow{4}{*}{$\mathbf{A B C}$} & $\mathbf{A}$ & $0.99 \approx 1$ & $0.99 \approx 1$ & 1.0 \\
\hline & B & $0.99 \approx 1$ & $0.99 \approx 1$ & $0.99 \approx 1$ \\
\hline & $\mathrm{C}$ & $0.99 \approx 1$ & $0.99 \approx 1$ & 1.0 \\
\hline & $\mathbf{N}$ & $2.3 \mathrm{e}-4 \approx 0$ & $-1.13 e-4 \approx 0$ & $1.5 \mathrm{e}-4 \approx 0$ \\
\hline \multirow{4}{*}{$\begin{array}{c}\text { Without } \\
\text { fault }\end{array}$} & $\mathbf{A}$ & $-2.8 \mathrm{e}-4 \approx 0$ & $-2.02 \mathrm{e}-3 \approx 0$ & $-2.02 \mathrm{e}-3 \approx 0$ \\
\hline & B & $-2.02 \mathrm{e}-3 \approx 0$ & $-2.3 \mathrm{e}-3 \approx 0$ & $-2.4 \mathrm{e}-3 \approx 0$ \\
\hline & $\mathrm{C}$ & $8.44 \mathrm{e}-05 \approx 0$ & $4.6 \mathrm{e}-4 \approx 0$ & $4.6 \mathrm{e}-4 \approx 0$ \\
\hline & $\mathbf{N}$ & $-1.9 \mathrm{e}-3 \approx 0$ & $-1.9 \mathrm{e}-3 \approx 0$ & $-1.9 \mathrm{e}-3 \approx 0$ \\
\hline
\end{tabular}

The above table shows that the fault type is clearly classified for faulty and unfaulty phases. 


\subsection{Tests results of fault locator}

The Back-Propagation Algorithm with sigmoid transfer function (TRAINBFG) is used for training the ten ANN-FL (ANN-AG, ANN-BG ... etc). As an example, the results of training for ANN-AG are shown in fig.(14). The recommendable goal 1e-05 is achieved after 4006 epochs.

The network is tested by new fault cases that unseen through the training process. Table (2) shows the fault location for different new fault types with different new conditions.

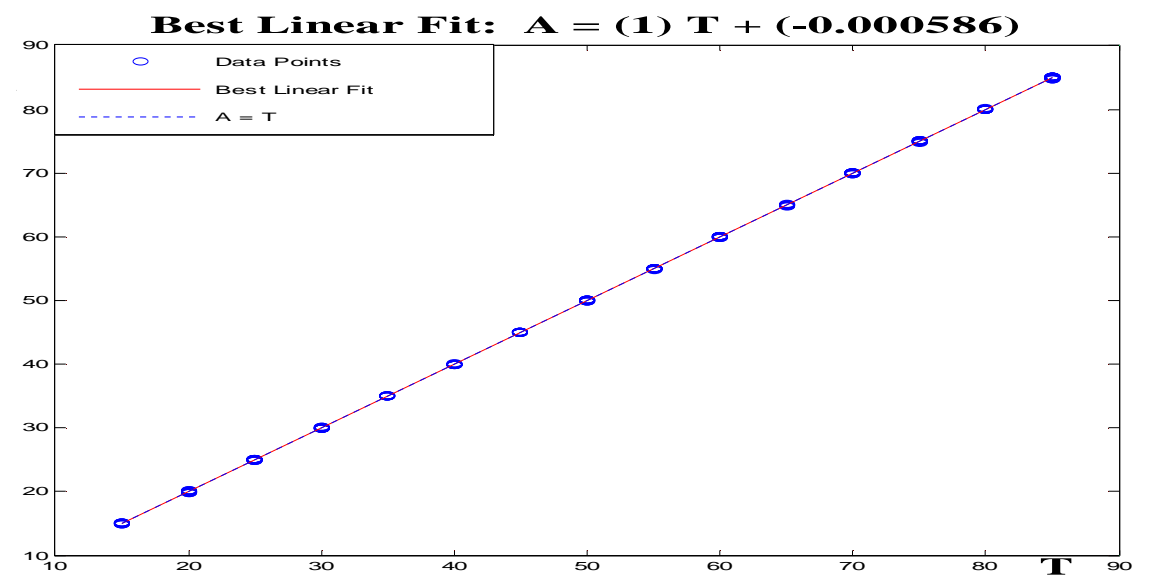

Fig.(14): The results of training ANN (FL, A-G),

T: recommendable target, A: resultant target.

\begin{tabular}{|c|c|c|c|c|c|c|}
\hline \multicolumn{7}{|c|}{ Table (2): The fault location for different new fault types } \\
\hline \multicolumn{7}{|c|}{ Fault A-G } \\
\hline \multirow{3}{*}{$\begin{array}{c}\mathbf{L}(\text { actual })=25[\mathrm{~km}] \\
\mathbf{R g}=0.01[\Omega]\end{array}$} & \multicolumn{2}{|c|}{ Angle $=15$ [degree] } & \multicolumn{2}{|c|}{ Angle $=37.5$ [degree] } & \multicolumn{2}{|c|}{ Angle $=67.5$ [degree $]$} \\
\hline & $\begin{array}{c}\mathrm{L} \\
\text { (estimated) }\end{array}$ & 25.076 & $\begin{array}{c}\mathbf{L} \\
\text { (estimated) }\end{array}$ & 24.921 & $\begin{array}{c}\mathbf{L} \\
\text { (estimated) }\end{array}$ & 25.061 \\
\hline & Error & $0.304 \%$ & Error & $0.316 \%$ & Error & $0.244 \%$ \\
\hline \multirow{3}{*}{$\begin{array}{c}\mathrm{L}(\text { actual })=45[\mathrm{~km}] \\
\mathrm{Rg}=25[\Omega]\end{array}$} & \multicolumn{2}{|c|}{ Angle $=7.5$ [degree $]$} & \multicolumn{2}{|c|}{ Angle=37.5 [degree] } & \multicolumn{2}{|c|}{ Angle $=67.5$ [degree] } \\
\hline & $\begin{array}{c}\mathbf{L} \\
\text { (estimated) }\end{array}$ & 44.9 & $\begin{array}{c}\mathrm{L} \\
\text { (estimated) }\end{array}$ & 4 & $\begin{array}{c}\mathbf{L} \\
\text { (estimated) }\end{array}$ & 45.031 \\
\hline & Error & $0.222 \%$ & Error & $0.1866 \%$ & Error & $0.068 \%$ \\
\hline \multirow{3}{*}{$\begin{array}{c}\mathrm{L}(\text { actual })=47[\mathrm{~km}] \\
\mathrm{Rg}=35[\Omega]\end{array}$} & \multicolumn{2}{|c|}{ Angle $=7.5$ [degree $]$} & \multicolumn{2}{|c|}{ Angle $=37.5$ [degree $]$} & \multicolumn{2}{|c|}{ Angle $=67.5$ [degree $]$} \\
\hline & $\begin{array}{c}\mathbf{L} \\
\text { (estimated) }\end{array}$ & 47.581 & $\begin{array}{c}\mathbf{L} \\
\text { (estimated) }\end{array}$ & 46.903 & $\begin{array}{c}\mathbf{L} \\
\text { (estimated) }\end{array}$ & 47.007 \\
\hline & Error & $1.236 \%$ & Error & $0.206 \%$ & Error & $0.0148 \%$ \\
\hline \multirow{3}{*}{$\begin{array}{c}\mathrm{L}(\text { actual })=75[\mathrm{~km}] \\
\mathrm{Rg}=45[\Omega]\end{array}$} & \multicolumn{2}{|c|}{ Angle=7.5 [degree] } & \multicolumn{2}{|c|}{ Angle $=37.5$ [degree] } & \multicolumn{2}{|c|}{ Angle $=67.5$ [degree] } \\
\hline & $\begin{array}{c}\mathbf{L} \\
\text { (estimated) }\end{array}$ & 74.922 & $\begin{array}{c}\mathbf{L} \\
\text { (estimated) }\end{array}$ & 75.299 & $\begin{array}{c}\mathbf{L} \\
\text { (estimated) }\end{array}$ & 74.946 \\
\hline & Error & $0.104 \%$ & Error & $0.398 \%$ & Error & $0.072 \%$ \\
\hline
\end{tabular}


The above table shows that the fault location is clearly determined with very small errors for different fault locations and conditions.

\section{Conclusions}

An efficient neural network-based fault detector for very fast HV transmission line protection and neural network-based fault locator has been proposed.

The results demonstrated the ability of ANNs to generalize the situation from the provided patterns and to accurately indicate the presence and location of faults using only one terminal line datum.

The neural fault detector and neural fault locator uses only standard deviations of $\left(D_{1}, D_{2}, D_{3}\right.$ and $\left.A_{3}\right)$ of discrete wavelet analysis for all instantaneous currents $\left(I_{A}, I_{B}, I_{C}\right.$ and $\mathrm{I}_{0}$ ).

The presented test results demonstrate the effectiveness and the precision of fault detection in a variety of fault situations including fault types, fault locations, fault inception angles and fault resistances.

The ANNs thus have the possibility to be used for on-line fault detection and location in transmission lines for one cycle before fault and half cycle after fault.

\section{References}

[1] T. Bouthiba, "Fault location in EHV transmission lines using Artificial Neural Networks", University of Science and Technology of Oran Faculty of Electrical Engineering B.P. 1505 El-Mnaouar, Oran 31000, Algeria -2004.

[2] Thompson Adu, Senior Member, IEEE, "A New Transmission Line Fault Locating System" IEEE Transactions on power delivery, vol. 16, NO. 4, October 2001.

[3] Fault Location Estimation in Power Systems with Universal Intelligent Tuning, T. A. S. Kawady, PHD theses, university of Darmstadt, 2005.

[4] P.Makming, S.Bunjongjit, A.Kunakorn, S.Jiriwibhakorn, and M.Kando, "Fault diagnosis in transmission lines using wavelet transform analysis", IEEE 2002.

[5] Amal F. Abdle-Gawad, "fault detector EHV transmission lines based on wavelet analysis", UPEC 2003, thalonek.

[6] Nan Zhang, "Advanced Fault Diagnosis Techniques and Their Role in Preventing Cascading Blackouts" Tsinghua University, China; December 2006.

[7] Wavelet Toolbox for Use with MATLAB, User's Guide Version 2.1, June 2001.

[8] Chunju Fan , K.K. Li, W.L. Chan, Weiyong Yu, " Study of protection scheme for transmission line based on wavelet transient energy ", ELSEVIER, Electrical power and energy systems 28 (2006), 459-470.

[9] Neural Network Toolbox for Use with MATLAB, User's Guide Version 4, March 2001. 